\title{
Protéolyse et texture des fromages à pâte cuite pressée. II. Influence de la chymosine et des conditions de fabrication
}

\author{
A Delacroix-Buchet ${ }^{1 *}, \mathrm{~S}$ Fournier 2 \\ 1 INRA, Station de recherches en technologie et analyses laitières, BP 89; \\ 2 Institut technique du Gruyère, zone centre, 39800 Poligny, France
}

(Reçu le 7 juin 1991; accepté le 25 octobre 1991)

\begin{abstract}
Résumé - Au cours de deux séries d'essais, 52 minifromages ont été fabriqués selon une technologique pâte cuite pressée en faisant varier les paramètres technologiques susceptibles de modifier la quantité de chymosine résiduelle et son activité protéolytique dans le fromage en cours d'affinage : $\mathrm{pH}$ au soutirage, température de chauffage en cuve, dose de présure apportée. Deux niveaux de chacun des facteurs ont été étudiés. Un témoin, sans chymosine, coagulé avec Endothia parasitica, a été introduit dans l'essai 2 . Les minifromages ont été affinés 40 j et 2 cycles de température d'affinage ont été comparés. Les conditions expérimentales montrent l'évolution de la protéolyse en cours d'affinage. La température d'affinage des fromages a un effet majeur sur la dégradation de la caséine $\alpha_{\mathrm{s} 1}$. La production de la fraction $\alpha_{\mathrm{s} 1-1}$ à partir de la caséine $\alpha_{\mathrm{s} 1}$ est ralentie par une élévation de la température de chauffage du mélange caillé-sérum en cuve de fabrication de $4^{\circ} \mathrm{C}$, phénomène qui ne peut être attribué que de façon mineure à l'activité de la chymosine. L'augmentation du chauffage en cuve de $4{ }^{\circ} \mathrm{C}$ génère, par contre, une accélération de la formation des fractions $\gamma$ à partir de la caséine $\beta$ liée à l'activation du système plasmine-plasminogène.
\end{abstract}

fromage / Gruyère / chymosine / paramètre de fabrication / protéolyse

Summary - Proteolysis and texture of Gruyère-type cheese. II. Influence of chymosin and cheese-making conditions. Fifty-two small cheeses were made under experimental scale Gruyère cheese process. The influence of cooking temperature, drawing off $\mathrm{pH}$ and rennet quantity were tested in 2 series of experiments on the amount of residual chymosin and its proteolytic activity in cheeses throughout their 40-d ripening period. Cheese ripening temperature had a major effect on $\alpha_{s 1}$-casein breakdown. Production of $\alpha_{s 1-1}$ fraction from $\alpha_{s 1}$-casein was retarded when the cooking temperature was raised in the vat from 52 to $56^{\circ} \mathrm{C}$. However, this phenomenon seemed to be only attributable for a minor part to differences in chymosin activity. A $4{ }^{\circ} \mathrm{C}$ increase in cooking temperature was also responsible for an acceleration of production of $\gamma$-fractions from $\beta$-casein due to an increase in plasmin activity.

cheese / Gruyère / chymosin / cheesemaking parameter / proteolysis

- Adresse actuelle : INRA, Station de recherches laitières, 78352 Jouy-en-Josas Cedex, France 


\section{INTRODUCTION}

En fabrication de fromages à pâte cuite pressée, un certain nombre de défauts moyens sont très généralement imputés à des problèmes de texture de pâte : texture trop ferme en Emmental, lainure en Comté. En dehors du rôle déterminant des teneurs en eau et graisse, l'évolution de la structure protéique du fromage au cours de l'affinage est également très importante (Grappin et Berdagué, 1989).

Cette protéolyse est sous la dépendance de différentes enzymes issues du lait, du coagulant ou des levains utilisés. Collin et al (1987) ont réalisé une première étude de la protéolyse dans les Gruyères de Comté. Ces auteurs ont montré que la variation de dégradation de la caséine $\alpha_{\mathrm{s} 1}$ était très liée à la température de la cave d'affinage et que celle de la caséine $\beta$ était davantage influencée par la fromagerie (composition du lait, nature des ferments lactiques, technologie) et la saison.

Plus spécifiquement, des travaux ont déjà été consacrés au rôle de la plasmine, une enzyme native du lait, dont la teneur varie beaucoup en fonction de la saison et du stade de lactation des animaux (Benslimane et al, 1990) notamment dans l'affinage des fromages à pâte cuite pressée (Trossat, 1988). D'autres ont été menés (Desmazeaud et al, 1976) ou sont en cours sur les levains.

Si l'on connaît bien l'activité spécifique de la présure sur la caséine $\kappa$, activité qui provoque la coagulation du lait et correspond à la première étape de la fabrication d'un fromage, on sait peu de choses en revanche sur le rôle possible de celle-ci dans l'affinage des fromages à pâte cuite pressée.

La présure, qui est un mélange de chymosine et de pepsine bovine dans une proportion d'activité coagulante d'environ
$80 / 20$, est le seul agent coagulant utilisé en fabrication de fromages à pâte cuite pressée d'appellation d'origine : Comté et Beaufort.

La présure ajoutée au lait est en grande partie éliminée avec le lactosérum lors de l'égouttage du caillé. Des auteurs ont essayé de quantifier la présure résiduelle dans les caillés : elle serait de l'ordre de $50 \%$ en fabrication de Camembert (Vassal et Gripon, 1984) et de $20 \%$ en fabrication de Cheddar (Holmes et al, 1977). Son activité au cours de l'affinage varie beaucoup d'un type de fromage à l'autre car les conditions de fabrication jouent un grand rôle dans la rétention et l'activité résiduelle de la présure dans le caillé.

Ainsi, plus le $\mathrm{pH}$ du lait et du sérum au décaillage est faible, plus la quantité de présure retenue dans le fromage est importante. Le chauffage dénature la présure et après un chauffage du caillé en cuve à $51-55{ }^{\circ} \mathrm{C}$, son activité résiduelle serait nulle ou faible (Matheson, 1981). Dans ces conditions, dans un caillé modèle type pâte cuite pressée, la pepsine serait totalement inactivée et l'activité résiduelle de la chymosine ne dépasserait pas $1,2 \%$ de son activité initiale (Garnot et Mollé, 1987). Mais les quantités exactes d'enzymes retenues ne sont pas précisément connues car les méthodes de détection sont encore imprécises. Des essais de dosage immunochimique des quantités d'enzymes résiduelles dans le fromage ont été réalisés par Collin et al (1988).

Dans les conditions physico-chimiques du fromage $(\mathrm{pH}, \mathrm{NaCl})$, la présure est stable et active (Gripon et al, 1975; Stadhouders et Hup, 1975). In vitro, l'action de la présure sur les caséines n'est pas spécifique mais dans les fromages, elle hydrolyse préférentiellement la caséine $\alpha_{s 1}$ en un fragment $\alpha_{\mathrm{s1-I}}$ (Mulvihill et Fox, 1979). On constate alors que mème présente en très faible quantité, elle joue un rôle impor- 
tant dans l'affinage de nombreux fromages : Cheddar, Camembert et Gouda (Green et Foster, 1974; Gripon et al, 1975 Visser et De Groot-Mostert, 1977). La dégradation de la caséine $\alpha_{s 1}$ intervient en quelques jours dans le Cheddar (Ledford et al, 1966). On ignore si de très faibles doses de chymosine ne pourraient pas jouer un rôle important dans des fromages à affinage long comme les fromages à pâte cuite pressée.

Des essais ont donc été conduits pour chercher à quantifier le rôle éventuel de la chymosine dans la protéolyse des fromages à pâte cuite pressée. L'influence des conditions de fabrication des fromages a été étudiée.

\section{MATÉRIEL ET MÉTHODES}

\section{Protocoles expérimentaux}

L'objet de la présente étude étant de mesurer l'influence de paramètres technologiques sur la protéolyse liée à l'activité de la chymosine dans les fromages à pâte cuite pressée, nous avons fabriqué selon cette technologie des minifromages expérimentaux en faisant varier les paramètres technologiques susceptibles, d'après la littérature, de modifier la quantité de chymosine résiduelle et son activité protéolytique dans le fromage en cours d'affinage : $\mathrm{pH}$ au soutirage (effet $\mathrm{pH}$ ) et température de chauffage en cuve (effet température). L'incidence de la dose de présure apportée a également été étudiée (effet dose).

Dans ce but, 2 séries d'essais ont été menées sur 2 semaines consécutives en novembre 1988 à la fromagerie expérimentale de I'INRA de Poligny, représentant au total 32 minifabrications individuelles.

Dans la première série d'essais (1), nous avons comparé indépendamment, mais simultanément, les effets $\mathrm{pH}$, température et dose à un témoin. Deux niveaux de chacun des facteurs ont été étudiés. Le protocole a été répété 5 fois, ce qui a représenté au total 20 fabrications (tableau la).
Dans la deuxième série d'essais (2), nous avons cumulé les effets "réputés" défavorables d'une part, et favorables d'autre part, à la rétention possible de chymosine dans le caillé. Les deux traitements (chymosine mini et maxi) ont été comparés à un témoin, sans chymosine, coagulé avec un extrait fongique (Endothia parasitica) détruit dans les conditions de chauffage en cuve des fromages à pâte cuite pressée. $\mathrm{Ce}$ protocole a été répété 4 fois et au total, 12 fabrications ont ainsi été réalisées (tableau lb).

Pour chaque série d'essais, les comparaisons entre traitements ont été effectuées le même jour avec le même lait. Les répétitions correspondent à des jours différents de fabrication.

\section{Fabrications}

Les fromages ont été fabriqués à partir d'un mélange de laits crus de 12 et $24 \mathrm{~h}$, standardisé en matière grasse à $29,5 \mathrm{~g} /$. Chaque jour, le lait, était réparti à raison de 11 I par cuve, dans 4 ou 3 minicuves ouvertes Guérin, selon la série expérimentale (essais 1 ou 2).

Le lait était alors réchauffé à $32{ }^{\circ} \mathrm{C}$ puis ensemencé respectivement 60 et $20 \mathrm{~min}$ avant emprésurage avec 1,5\% d'un mélange de souches de Streptococcus salivarius subsp thermophilus (mélange STB 01, Ets Boll , Arpajon) cultivé sur lait écrémé et $0,5 \%$ d'un mélange de Lactobacillus helveticus (souches CNRZ 32 et CNRZ 303 ) cultivées sur milieu antiphage tamponné Phagex (Standa Industrie, Caen). Les laits étaient ensuite coagulés avec une dose de coagulant permettant une prise en $40 \mathrm{~min}$ pour le témoin et 20 min pour le traitement "effet dose".

Le coagulant utilisé était soit un extrait de présure liquide Granday (Beaune) à $820 \mathrm{mg}$ de chymosine par litre, soit un extrait fongique d'Endothia parasitica (Pfizer France, Orsay). Le moment de la coagulation était déterminé à l'aide du coagulomètre INRA (Bellon et al, 1988). Le chauffage du mélange caillé sérum et son maintien en température était assuré par programmation du cycle thermique du liquide caloporteur circulant dans la double paroi des cuves.

Pour étudier l'effet pH de l'essai 1 et l'effet chymosine maxi de l'essai 2 , le pH du sérum au soutirage était abaissé, en début de maturation du lait, de 0,1 unité par addition de glucono- 
Tableau I. Schémas expérimentaux. a: essai $1 ;$ b: essai 2.

Experimental schemes: $a$ : trial 1; b: trial 2.

\begin{tabular}{|c|c|c|c|c|}
\hline $\begin{array}{l}\text { Modification } \\
\text { technologique }\end{array}$ & $\begin{array}{l}\text { Cuve } 1 \\
\text { Témoin }\end{array}$ & $\begin{array}{l}\text { Cuve } 2 \\
\text { Effet pH }\end{array}$ & $\begin{array}{l}\text { Cuve } 3 \\
\text { Effet } T^{\circ}\end{array}$ & $\begin{array}{l}\text { Cuve } 4 \\
\text { Effet dose }\end{array}$ \\
\hline \multicolumn{5}{|l|}{ a: essai 1} \\
\hline Dose de présure & 1 dose & 1 dose & 1 dose & 2 doses \\
\hline Température de chauffage & $52^{\circ} \mathrm{C}$ & $52^{\circ} \mathrm{C}$ & $56^{\circ} \mathrm{C}$ & $52^{\circ} \mathrm{C}$ \\
\hline \multirow[t]{2}{*}{$\mathrm{pH}$ au soutirage } & normal & $\begin{array}{l}\text { bas } \\
(-0,1 \text { unité } \mathrm{pH})\end{array}$ & normal & normal \\
\hline & $\begin{array}{l}\text { Chymosine } \\
\text { mini }\end{array}$ & $\begin{array}{l}\text { Endothia } \\
\text { parasitica }\end{array}$ & $\begin{array}{l}\text { Chymosine } \\
\text { maxi }\end{array}$ & \\
\hline \multicolumn{5}{|l|}{ a : essai 2} \\
\hline Dose de présure & 1 dose & 1 dose & 2 doses & \\
\hline Température de chauffage & $56^{\circ} \mathrm{C}$ & $56^{\circ} \mathrm{C}$ & $52^{\circ} \mathrm{C}$ & \\
\hline $\mathrm{pH}$ au soutirage & normal & normal & $\begin{array}{l}\text { bas } \\
(-0,1 \text { unité } \mathrm{pH})\end{array}$ & \\
\hline
\end{tabular}

delta-lactone (GDL) à raison de $0,3 \mathrm{~g} / \mathrm{de}$ lait (Serpellonni et al, 1989).

Les temps technologiques ont été adaptés aux modifications technologiques pour obtenir après $20 \mathrm{~h}$ de pressage, des fromages aussi comparables que possible en valeurs de $\mathrm{pH}$ et d'extrait sec, c'est-à-dire possédant des valeurs d'activité de l'eau voisines. Ainsi, la réduction du temps de coagulation a été associée à une réduction du temps de durcissement et l'élévation de le température de cuisson du grain en cuve a été compensée par une réduction de son temps de brassage (tableau II).

Après soutirage par gravité à $52^{\circ} \mathrm{C}$ du mélange caillé-sérum dans un moule, les fromages ont été pressés $6 \mathrm{~h}$ dans une enceinte thermostatée à $42{ }^{\circ} \mathrm{C}$ dans laquelle ils ont été maintenus 14 autres heures, sans pressage, jusqu'à leur refroidissement à $30^{\circ} \mathrm{C}$, avant d'être démoulés.

\section{Affinage}

Après démoulage, les minifromages obtenus, de forme cylindrique, pèsent environ $900 \mathrm{~g}$, ont un diamètre de $15 \mathrm{~cm}$ et une hauteur de $4 \mathrm{~cm}$. Pour permettre des analyses répétées en cours d'affinage, sans modifier le cycle, ni les conditions d'affinage chaque fromage a été découpé en 8 portions égales (fig 1 ).

Les conditions d'affinage ont été choisies de manière à faire ressortir au mieux l'incidence de l'activité résiduelle de la chymosine éventuellement présente dans la pâte du fromage et à diminuer, voire éviter l'incidence d'autres facteurs de la protéolyse. En particulier, les fromages n'ont pas été salés pour maintenir une activité de l'eau élevée et accroître l'activité protéolytique de la présure très sensible à la teneur en sel (Sanogo et al, 1987). Les portions ont été traitées individuellement au démoulage avec un 
Tableau II. Diagramme des fabrications expérimentales de gruyères.

Standard manufacturing procedure for experimental gruyère-type cheese.

$\begin{array}{lll}\text { Opérations } & \begin{array}{l}\text { Durée de l'opération ou } \\ \text { (temps avant emprésurage) }\end{array} & \begin{array}{l}\text { Température } \\ \left({ }^{\circ} \mathrm{C}\right)\end{array}\end{array}$

Préparation du lait

Addition des streptocoques

Addition des lactobacilles

Addition de la présure

(temps de prise de base) a

durcissement ${ }^{b}$

Décaillage

Brassage avec chauffage

Brassage :

avec maintien à $52^{\circ} \mathrm{C} b$

avec maintien à $56^{\circ} \mathrm{C}$ b

Soutirage

Pressage à $150 \mathrm{~g} / \mathrm{cm}^{2}$

Maintien dans la presse (la veille)

$(60 \mathrm{~min})$

(20 min)

32

32

32

$40 \mathrm{~min}$

$4 \mathrm{~min}$

32

$3 \mathrm{~min}$

32

$35 \mathrm{~min}$

$32 \rightarrow 52$ ou 56

$40 \mathrm{~min}$

52

$30 \mathrm{~min}$ puis $10 \mathrm{~min}$

56 puis $56 \rightarrow 52$

52

$6 \mathrm{~h}$

42

$14 \mathrm{~h}$

$42 \rightarrow 30$

a : Valeurs modifiées en fonction des facteurs étudiés. ${ }^{b}$ : Valeurs pouvant être modulées pour obtenir des fromages avec des caractéristiques homogènes.

a Values modified according to factors under study; ${ }^{b}$ Values which can be modulated in order to obtain cheeses with homogenous characteristics.

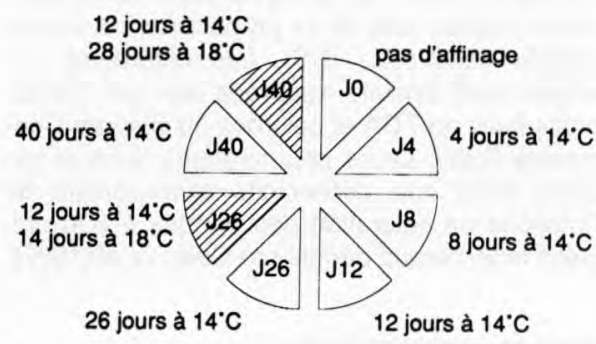

Fig 1. Schéma d'affinage des portions de fromages.

Ripening scheme for cheese portions. antifongique de surface (pymaricine) pour empêcher le développement d'une morge à leur surface. Elles ont été emballées séparément sous vide dans des sacs, imperméables, à l'eau et aux gaz, en poléthylène-propylène (Grace Cryovac SA, Épernon) pour éviter leur déshydratation.

Les portions ont été affinées à basse température $\left(14^{\circ} \mathrm{C}\right)$ pour limiter le développement des bactéries lactiques susceptibles de masquer l'action de la chymosine. A titre de comparaison, 2 des 8 portions ont été affinées à $18^{\circ} \mathrm{C}$ après 12 jours de préaffinage à $14^{\circ} \mathrm{C}$. La durée totale d'affinage a été de 40 jours. 


\section{Méthodes}

\section{Analyses des laits et des sérums}

Les prélèvements sont effectués soit sur le lait réceptionné, le jour de la fabrication pour les analyses microbiologiques retenues pour caractériser la qualité bactériologique des laits de fabrication, soit sur le lait de cuve avant emprésurage pour les analyses chimiques et le contrôle de l'ensemencement en levain des cuves, ou sur les sérums au moment du soutirage pour connaître les pertes en matière utile de chacune des cuves et contrôler les conditions technologiques.

- Matière grasse : méthode butyrométrique de Gerber (norme NF V-04210).

- Matière protéique totale : méthode colorimétrique au Noir Amido (norme NF V-04216).

- Analyses microbiologiques : numération de la flore totale (Plate Count Agar, 3 jours à $30^{\circ} \mathrm{C}$ ) sur le lait réceptionné et le lait avant emprésurage, numérations de la flore psychrotrophe (Plate Count Agar, 10 jours à $7^{\circ} \mathrm{C}$ ) et de la flore

Tableau III. Nature et répartition des analyses effectuées sur les portions de fromages en cours d'affinage.

Nature and distribution of tests carried out on cheese portions during cheese ripening.

\begin{tabular}{lll}
\hline $\begin{array}{l}\text { Stade } \\
\text { d'affinage }\end{array}$ & Portions & $\begin{array}{l}\text { Nature } \\
\text { des analyses }\end{array}$ \\
\hline J0 & 1 & $\begin{array}{l}\text { Matière grasse, } \\
\text { calcium }\end{array}$ \\
$\begin{array}{l}\text { J0, J12 } \\
\text { etJ40 }\end{array}$ & $1,4,7$ et 8 & $\begin{array}{l}\text { pH, extrait sec, } \\
\text { azote total } \\
\text { et fractions azotées }\end{array}$ \\
$\begin{array}{l}\text { J0, J4, J8, } \\
\text { J12, J26 } \\
\text { et J40 }\end{array}$ & 1 à 8 & Fractions caséines \\
\hline
\end{tabular}

coliforme (Violet Red Bile Agar, 18 à $24 \mathrm{~h}$ à $30^{\circ} \mathrm{C}$ ) sur le lait réceptionné.

\section{Analyses des fromages}

Le tableau III précise la nature et la fréquence des analyses réalisées.

$-\mathrm{pH}$ : mesure à l'aide d'un $\mathrm{pH}$-mètre à électrode combinée placée au contact d'un broyat de fromage tassé dans un godet.

- Extrait sec : dosage selon la norme FIL 4A (1982).

- Matière grasse : méthode butyrométrique de Heiss (1961).

- Calcium : dosage complexométrique selon la technique de Pearce (1977) adaptée au fromage par Jeunet (communication personnelle)

- Azote total et fractions azotées : dosage par la méthode Kjeldahl de l'azote total (NT), de l'azote soluble dans l'eau (NS) après préparation selon la méthode de Kuchroo et Fox (1982) et de l'azote soluble dans l'acide phosphotungstique (NPT) après préparation selon la technique de Gripon et al (1975).

- Fractions caséines : analyse quantitative des principales caséines et de leurs produits de dégradation $\left(\alpha_{s 1}, \beta, \alpha_{s 1-1}, \beta\right.$ dégradées, $\left.\gamma_{1}, \gamma_{2}, \gamma_{3}\right)$ après séparation électrophorétique horizontale (cuve Sebia, Issy-les-Moulineaux) des caséines et lecture densitométrique (lecteur Helena France SA, Saint-Leu-la-Forêt) de plaque d'électrophorèse selon la technique d'Uriel (1966), reprise par Collin et al (1987) et Buchet (1987). La caséine entière est préparée par dissolution dans $5 \mathrm{ml}$ d'urée $9 \mathrm{~mol} / \mathrm{l}$ contenant $1 \%$ de $\beta$ mercaptoéthanol, de $0,3 \mathrm{~g}$ du culot de centrifugation obtenu lors de la préparation de l'azote soluble dans l'eau (NS). Les différentes caséines sont ensuite séparées sur gel PAGE, précipitées au TCA et colorées au Bleu de Coomassie R250. Leurs pourcentages dans la caséine totale sont déterminés après lecture de l'intensité de coloration des bandes à $590 \mathrm{~nm}$, selon la technique décrite par Collin et al (1987).

\section{Analyses statistiques}

Pour chaque variable sont présentés les moyennes et les écarts types calculés aux différents stades d'affinage. 
L'influence respective des différents facteurs sur la protéolyse des fromages a été estimée grâce à l'analyse de variance et visualisée par l'analyse factorielle discriminante.

Les analyses statistiques ont êté réalisées à partir des logiciels Microstat, élaborés par l'ITCF (Boigneville) (4 $4^{\theta}$ version $\left.1987-1988\right)$.

\section{RÉSULTATS ET DISCUSSION}

\section{Maîtrise des paramètres de fabrication et des facteurs étudiés}

\section{Maîtrise du facteur pH et caractéristiques des fromages à $20 \mathrm{~h}$}

Les résultats sont rassemblés dans les tableaux IVa et IVb respectivement pour les séries d'essais 1 et 2 .

La baisse volontaire du $\mathrm{pH}$ du lait à l'emprésurage de $-0,1$ unité, par addition de GDL, se retrouve en fin de travail dans les valeurs de $\mathrm{pH}$ mesurées sur les sérums au soutirage des cuves $(-0,11$ unité $\mathrm{pH}$ pour le traitement « $\mathrm{pH}$ ” de l'essai 1 et $-0,09$ unité $\mathrm{pH}$ pour le traitement "chymosine maxi" de l'essai 2 par rapport au $\mathrm{pH}$ du traitement témoin de chaque essai).

Les fromages à $20 \mathrm{~h}$ ont un extrait sec (ES) voisin de $61,5 \%$ de leur poids et un $\mathrm{pH}$ de l'ordre de 5,20 . Leurs teneurs moyennes en matière grasse dans l'ES (G/ S), en indice d'humidité rapportée à l'extrait sec dégraissé (H/ESD) et en calcium dans I'ES sont respectivement de 47,6 , 1,20 et $1,60 \mathrm{~g} / 100 \mathrm{~g}$. Toutes ces valeurs sont des valeurs normales pour des fromages à pâte cuite pressée type gruyère.

L'analyse des valeurs d'ES, de G/S et de H/ESD montre une très bonne homogénéité entre les différents traitements d'une même série d'essais. C'était l'objectif pour- suivi en modifiant les temps technologiques pour corriger les différences d'égouttage des caillés liées soit à des temps de coagulation variant du simple au double, soit à des températures de chauffage en cuve présentant des écarts relatifs importants pour la plage de température considérée.

Une différence significative $(P<0,05)$ apparaît dans l'essai 1 , entre la teneur en calcium des fromages issus du traitement $\mathrm{pH}$ et celle des autres fromages $(-50 \mathrm{mg} /$ $100 \mathrm{~g}$ de fromage). La différence observée est liée à la différence des $\mathrm{pH}$ des sérums au soutirage des fromages. La baisse volontaire du pH du lait est responsable d'une plus forte déminéralisation du caillé. Cette observation n'est pas significative dans l'essai 2 du fait d'une variabilité relativement importante $\mathrm{du} \mathrm{pH}$ initial du lait entre jours de fabrication. L'apport de GDL dans les cuves n'a cependant pas affecté suffisamment la solubilité du calcium pour pouvoir modifier la stabilité thermique de la chymosine. La fixation des ions calcium en stabilisant la structure moléculaire de l'enzyme (Dahlquist et al, 1976) peut en effet éviter sa dénaturation thermique (Garnot et Mollé, 1987).

\section{Variabilité et composition moyenne des fromages au cours des principaux stades d'affinage}

Les résultats sont présentés dans le tableau V.

L'extrait sec des portions de fromage est demeuré stable tout au long des 40 jours d'affinage. L'affinage sous film de polyéthylène a donc bien maintenu l'hydratation des fromages qui a varié de moins de $1 \%$ du début à la fin de l'affinage.

L'affinage des fromages à $14{ }^{\circ} \mathrm{C}$ par rapport à un affinage à $18^{\circ} \mathrm{C}$ a considérablement réduit la production d'azote so- 
Tableau IV. $\mathrm{pH}$ des sérums au soutirage des cuves et caractéristiques physico-chimiques des fromages à $20 \mathrm{~h}$ (moyenne $\bar{X}$, écart type $\sigma$ et analyse de la variance en fonction des traitements). a : essai $1 ; b$ : essai 2.

$\mathrm{pH}$ of whey at drawing off and physico-chemical characteristics of cheeses at $20 \mathrm{~h}$ (mean $\bar{X}, S D \sigma$ and variance analysis according to the different treatments). $a:$ trial $1 ; b:$ trial 2.

a

\begin{tabular}{|c|c|c|c|c|c|c|c|}
\hline \multirow[t]{2}{*}{ Variables } & \multirow{2}{*}{$\begin{array}{l}\bar{X} \\
\pm(s)\end{array}$} & \multicolumn{4}{|c|}{ Traitement (essai 1) } & \multirow{2}{*}{$\begin{array}{c}\text { Seuil de } \\
\text { signification }\end{array}$} & \multirow{2}{*}{$\begin{array}{l}\text { Test de } \\
\text { Newman } \\
\text { Keuls }\end{array}$} \\
\hline & & $\begin{array}{l}\text { 1: } \\
\text { témoin }\end{array}$ & $\begin{array}{l}\text { 2: } \\
\text { pH }\end{array}$ & $\begin{array}{l}\text { 3: } \\
\text { température }\end{array}$ & $\begin{array}{l}\text { 4: } \\
\text { dose }\end{array}$ & & \\
\hline $\begin{array}{l}\mathrm{pH} \text { du sérum } \\
\text { au soutirage }\end{array}$ & $\begin{array}{c}6,45 \\
(0,01)\end{array}$ & $\begin{array}{c}6,48 \\
(0,01)\end{array}$ & $\begin{array}{c}6,37 \\
(0,02)\end{array}$ & $\begin{array}{c}6,47 \\
(0,01)\end{array}$ & $\begin{array}{l}6,47 \\
(0,02)\end{array}$ & $* * *$ & 1432 \\
\hline Extrait sec a & $\begin{array}{c}61,49 \\
(0,32)\end{array}$ & $\begin{array}{c}61,22 \\
(0,13)\end{array}$ & $\begin{array}{l}61,79 \\
(0,41)\end{array}$ & $\begin{array}{c}61,62 \\
(0,16)\end{array}$ & $\begin{array}{l}61,31 \\
(0,45)\end{array}$ & NS & \\
\hline Gras/sec ${ }^{b}$ & $\begin{array}{c}47,63 \\
(0,85)\end{array}$ & $\begin{array}{l}47,76 \\
(1,06)\end{array}$ & $\begin{array}{l}47,58 \\
(0,88)\end{array}$ & $\begin{array}{l}47,71 \\
(0,78)\end{array}$ & $\begin{array}{l}47,46 \\
(0,61)\end{array}$ & NS & \\
\hline $\begin{array}{l}\text { Humidité/extrait } \\
\text { sec dégraissé }\end{array}$ & $\begin{array}{c}1,20 \\
(0,02)\end{array}$ & $\begin{array}{c}1,21 \\
(0,02)\end{array}$ & $\begin{array}{c}1,18 \\
(0,02)\end{array}$ & $\begin{array}{c}1,19 \\
(0,01)\end{array}$ & $\begin{array}{c}1,20 \\
(0,03)\end{array}$ & NS & \\
\hline $\mathrm{pH}$ & $\begin{array}{c}5,18 \\
(0,05)\end{array}$ & $\begin{array}{c}5,16 \\
(0,06)\end{array}$ & $\begin{array}{c}5,17 \\
(0,06)\end{array}$ & $\begin{array}{c}5,20 \\
(0,04)\end{array}$ & $\begin{array}{l}5,19 \\
(0,05)\end{array}$ & NS & \\
\hline Calcium ${ }^{c}$ & $\begin{array}{c}1,59 \\
(0,04)\end{array}$ & $\begin{array}{c}1,60 \\
(0,03)\end{array}$ & $\begin{array}{c}1,55 \\
(0,01)\end{array}$ & $\begin{array}{c}1,63 \\
(0,04)\end{array}$ & $\begin{array}{c}1,60 \\
(0,05)\end{array}$ & $*$ & 3142 \\
\hline
\end{tabular}

b

\begin{tabular}{llllll}
\hline Variables & $\bar{X}$ & & \multicolumn{2}{c}{ Traitement (essai 2) } & $\begin{array}{c}\text { Seuil de } \\
\text { signification }\end{array}$ \\
& $\pm(s)$ & 1: & 2: & 3: & \\
& & $\begin{array}{c}\text { Chymosine } \\
\text { mini }\end{array}$ & $\begin{array}{c}\text { Endothia } \\
\text { parasitica }\end{array}$ & $\begin{array}{c}\text { Chymosine } \\
\text { maxi }\end{array}$ & \\
\hline
\end{tabular}

\begin{tabular}{|c|c|c|c|c|c|}
\hline $\begin{array}{l}\mathrm{pH} \text { du sérum } \\
\text { au soutirage }\end{array}$ & $\begin{array}{c}6,57 \\
(0,08)\end{array}$ & $\begin{array}{c}6,58 \\
(0,09)\end{array}$ & $\begin{array}{c}6,61 \\
(0,08)\end{array}$ & $\begin{array}{c}6,52 \\
(0,08)\end{array}$ & NS \\
\hline Extrait $\mathrm{sec}^{\mathrm{a}}$ & $\begin{array}{l}61,58 \\
(0,50)\end{array}$ & $\begin{array}{l}61,34 \\
(0,43)\end{array}$ & $\begin{array}{l}61,76 \\
(0,66)\end{array}$ & $\begin{array}{l}61,64 \\
(0,35)\end{array}$ & NS \\
\hline Gras/sec b & $\begin{array}{c}47,59 \\
(1,01)\end{array}$ & $\begin{array}{c}47,27 \\
(1,03)\end{array}$ & $\begin{array}{l}47,63 \\
(0,98)\end{array}$ & $\begin{array}{c}47,86 \\
(1,00)\end{array}$ & NS \\
\hline $\begin{array}{l}\text { Humidité/extrait } \\
\text { sec dégraissé }\end{array}$ & $\begin{array}{c}1,19 \\
(0,02)\end{array}$ & $\begin{array}{c}1,20 \\
(0,01)\end{array}$ & $\begin{array}{c}1,18 \\
(0,02)\end{array}$ & $\begin{array}{c}1,19 \\
(0,02)\end{array}$ & NS \\
\hline $\mathrm{pH}$ & $\begin{array}{c}5,24 \\
(0,05)\end{array}$ & $\begin{array}{c}5,23 \\
(0,03)\end{array}$ & $\begin{array}{c}5,25 \\
(0,06)\end{array}$ & $\begin{array}{c}5,24 \\
(0,06)\end{array}$ & NS \\
\hline Calcium c & $\begin{array}{c}1,61 \\
(0,07)\end{array}$ & $\begin{array}{c}1,63 \\
(0,09)\end{array}$ & $\begin{array}{c}1,64 \\
(0,04)\end{array}$ & $\begin{array}{c}1,56 \\
(0,06)\end{array}$ & NS \\
\hline
\end{tabular}

${ }^{a} \mathrm{~g} / 100 \mathrm{~g}$ de fromage; ${ }^{\mathrm{b}} \% ;{ }^{c} \mathrm{~g} / 100 \mathrm{~g}$ d'extrait sec; NS : Non-Significatif; ${ }^{*}: P<0,05 ;{ }^{* * *}: P<0,001$.

${ }^{a}$ g/100 $\mathrm{g}$ of cheese; ${ }^{b} \% ;{ }^{c} \mathrm{~g} / 100 \mathrm{~g}$ of dry matter; NS : Non-Significant; $": \mathrm{P}<0.05 \cdots " \mathrm{P}<0.001$. 
Tableau V. Composition physico-chimique moyenne des fromages aux 4 principaux stades d'affinage (moyenne et écart type). $a$ : essai $1 ; b$ : essai 2.

Physico-chemical composition (mean and SD) of the cheeses at the 4 main stages of the ripening process. a: trial $1 ;$ b: trial 2 .

\begin{tabular}{lllll}
\hline $\begin{array}{l}\text { Variables } \\
(n=20)\end{array}$ & \multicolumn{4}{c}{ Stades d'affinage (essai 1$)$} \\
\cline { 2 - 5 } & Jo & $J 12$ & $\begin{array}{c}J 40 \\
\left(14^{\circ} \mathrm{C}\right)\end{array}$ & $\begin{array}{c}\mathrm{J} \\
\left(18^{\circ} \mathrm{C}\right)\end{array}$ \\
\hline
\end{tabular}

\begin{tabular}{|c|c|c|c|c|}
\hline $\mathrm{pH}$ & $\begin{array}{c}5,30 \\
( \pm 0,03)\end{array}$ & $\begin{array}{c}5,46 \\
( \pm 0,05)\end{array}$ & $\begin{array}{c}5,64 \\
( \pm 0,06)\end{array}$ & $\begin{array}{c}5,72 \\
( \pm 0,10)\end{array}$ \\
\hline Extrait $\sec ^{a}$ & $\begin{array}{c}61,49 \\
( \pm 0,32)\end{array}$ & $\begin{array}{c}61,31 \\
( \pm 0,34)\end{array}$ & $\begin{array}{c}61,40 \\
( \pm 0,59)\end{array}$ & $\begin{array}{c}61,31 \\
( \pm 0,69)\end{array}$ \\
\hline${ }^{*} \mathrm{NS} / \mathrm{NT}^{\mathrm{b}}$ & $\begin{array}{r}3,37 \\
( \pm 0,17)\end{array}$ & $\begin{array}{r}6,40 \\
( \pm 0,32)\end{array}$ & $\begin{array}{c}13,42 \\
( \pm 0,77)\end{array}$ & $\begin{array}{c}17,12 \\
( \pm 1,39)\end{array}$ \\
\hline * NPT/NT ${ }^{b}$ & $\begin{array}{c}0,66 \\
( \pm 0,05)\end{array}$ & $\begin{array}{c}1,28 \\
( \pm 0,14)\end{array}$ & $\begin{array}{c}2,96 \\
( \pm 0,31)\end{array}$ & $\begin{array}{r}4,06 \\
( \pm 0,62)\end{array}$ \\
\hline \multicolumn{5}{|l|}{$b$ : essai 2} \\
\hline $\mathrm{pH}$ & $\begin{array}{r}5,30 \\
( \pm 0,02)\end{array}$ & $\begin{array}{c}5,45 \\
( \pm 0,02)\end{array}$ & $\begin{array}{c}5,66 \\
( \pm 0,03)\end{array}$ & $\begin{array}{c}5,76 \\
( \pm 0,05)\end{array}$ \\
\hline Extrait sec ${ }^{a}$ & $\begin{array}{c}61,58 \\
( \pm 0,50)\end{array}$ & $\begin{array}{c}61,50 \\
( \pm 0,43)\end{array}$ & $\begin{array}{c}61,14 \\
( \pm 0,57)\end{array}$ & $\begin{array}{c}61,21 \\
( \pm 0,70)\end{array}$ \\
\hline${ }^{*} \mathrm{NS} / \mathrm{NT} \mathrm{b}^{\mathrm{b}}$ & $\begin{array}{c}3,37 \\
( \pm 0,14)\end{array}$ & $\begin{array}{c}6,11 \\
( \pm 0,24)\end{array}$ & $\begin{array}{c}12,44 \\
( \pm 0,56)\end{array}$ & $\begin{array}{c}15,75 \\
( \pm 0,99)\end{array}$ \\
\hline${ }^{* *}$ NPT/NT & $\begin{array}{c}0,65 \\
( \pm 0,10)\end{array}$ & $\begin{array}{c}1,26 \\
( \pm 0,16)\end{array}$ & $\begin{array}{c}2,66 \\
( \pm 0,50)\end{array}$ & $\begin{array}{c}4,00 \\
( \pm 0,60)\end{array}$ \\
\hline
\end{tabular}

a $\mathrm{g} / 100 \mathrm{~g}$ de fromage; ${ }^{\mathrm{b}} \%$; - NS : azote soluble dans l'eau; “ NPT : azote soluble dans l'acide phosphotungstique.

a $\mathrm{g} / 100 \mathrm{~g}$ of cheese; ${ }^{\mathrm{b}} \%$; " NS : water-soluble nitrogen; * NPT : phosphotungstic acid-soluble nitrogen.

luble à pH 4,6 et surtout d'azote soluble dans l'acide phophotungstique (respectivement $-27 \%$ et $-53 \%$ en moyenne pour l'ensemble des essais).
On sait que l'activité des bactéries lactiques se traduit par une augmentation importante des produits azotés de très faible poids moléculaire, ce que représente l'azote soluble dans l'acide phosphotungstique (Desmazeaud et al, 1976; Kleter, 1976; Visser, 1977; O'Keefe et al, 1978).

Le choix de la température d'affinage a donc bien limité l'activité des bactéries lactiques, objectif que nous nous étions fixés pour mieux mettre en évidence l'effet possible de nos traitements technologiques sur l'activité résiduelle de la chymosine.

L'affinage des fromages dans l'essai 1 et dans l'essai 2 semble relativement comparable, à l'examen de l'évolution de leurs $\mathrm{pH}: 5,30$ à 5,65 pour un affinage à $14^{\circ} \mathrm{C}$ et 5,30 à 5,74 pour un affinage à $18^{\circ} \mathrm{C}$ en moyenne, quelle que soit la série d'essais.

\section{Influence des facteurs technologiques sur la protéolyse primaire}

La protéolyse primaire correspond à la dégradation des caséines en fractions de haut poids moléculaire dont l'apparition peut être facilement suivie par électrophorèse. Nous nous sommes principalement intéressés aux caséines $\alpha_{s 1}$ et $\beta$ et à l'apparition de leurs produits respectifs de dégradation, les fractions $\alpha_{\mathrm{s} 1}$ et $\gamma$ (total des fractions $\gamma_{1}, \gamma_{2}$ et $\gamma_{3}$ ). Nous avons également observé la vitesse de dégradation de la caséine $\alpha_{\mathrm{s} 2}$.

\section{Dégradation de la caséine $\alpha_{\mathbf{s 1}}$}

La dégradation de la caséine $\alpha_{s 1}$ ne semble pas affectée par les traitements étudiés dans l'essai 1 à l'exception du traitement température de chauffage en cuve. En effet, avec le chauffage en cuve à $56^{\circ} \mathrm{C}$, nous observons un ralentissement 
de la dégradation de la caséine $\alpha_{s 1}$, significatif à $\mathrm{J} 40(P<0,05)$ et perceptible dès J8 (tableau Vla). Bien que peu importante (1 point en moyenne sur la proportion de caséine $\alpha_{s 1}$ dans la caséine totale), cette différence montre qu'une élévation de la température de chauffage en cuve de $4^{\circ} \mathrm{C}$ ralentit la dégradation de la caséine $\alpha_{\mathrm{s} 1}$.

Cette observation est confirmée par la vitesse d'apparition de la fraction $\alpha_{s 1 \text { 1. }}$. $A$ $\mathrm{JO}$, la bande d'électrophorèse correspondant à cette fraction est inexistante. À J4, elle apparaît mais n'est dissociée de celle de la caséine $\alpha_{s 1}$ que dans $1 / 3$ environ des cas : elle représenterait alors de l'ordre de $3 \%$ de l'ensemble des fractions caséines. À partir de J8, la différence de cinétique d'apparition de la fraction $\alpha_{s 1-1}$ entre le traitement température et les autres traitements est très significative $(P<0,001)$ (tableau Vla et fig 2a). L'écart relatif entre les proportions de fraction $\alpha_{s 1-1}$ dans la caséine totale mesurées entre le fromage témoin et le fromage fabriqué à $56{ }^{\circ} \mathrm{C}$, tous deux affinés à $14^{\circ} \mathrm{C}$, est un peu plus important à $\mathrm{J} 12$ qu'à $\mathrm{J} 40$ (respectivement $+25 \%$ et $+19 \%$ en moyenne pour les 5 répétitions de l'essai 1 ).

Les résultats de l'essai 2 montrent une augmentation de la dégradation de la caséine $\alpha_{s 1}$ et une accélération de l'apparition de la fraction $\alpha_{\mathrm{s} 1-1}$ seulement entre les traitements chymosine mini et chymosine maxi ou Endothia parasitica et chymosine maxi (tableau Vlb et fig 2b). Cette différence est du même ordre que celle mesurée entre le traitement température et le traitement témoin de l'essai 1 , ce qui confirme l'absence d'effet des autres paramètres de fabrication étudiés (dose et $\mathrm{pH}$ ).

Si l'on définit l'action de la chymosine dans les fromages comme l'hydrolyse préférentielle de la caséine $\alpha_{\mathrm{s} 1}$ pour produire un fragment $\alpha_{\mathrm{s} 1-1}$ (Mulvihill et Fox, 1979), un chauffage en cuve de $52^{\circ} \mathrm{C}$ au lieu
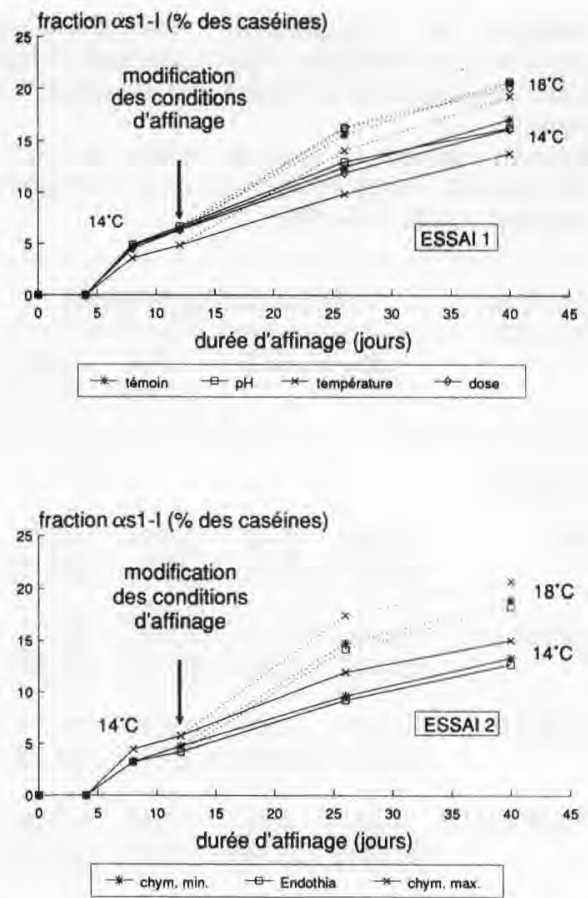

Fig 2. Évolution au cours de l'affinage de la fraction $\alpha_{s 1-1}$ exprimée en $\%$ des caséines totales.

Evolution during cheese ripening of the $\alpha_{s 1-1}$ fraction expressed as percentage of whole casein.

de $56{ }^{\circ} \mathrm{C}$ provoquerait une dénaturation moindre de la présure. Cette observation rejoint celle de Garnot et Mollé (1987). Ces auteurs n'ont pas non plus observé de différence dans l'activité résiduelle de la chymosine ajoutée à une dose simple ou double dans des laits chauffés $60 \mathrm{~min}$ à $53^{\circ} \mathrm{C}$ après emprésurage. Par contre, ils soulignaient l'importance d'une diminution du $\mathrm{pH}$ des laits à l'emprésurage de 6,75 à 6,50 sur l'augmentation de stabilité thermique de la chymosine. La variation de $\mathrm{pH}$ induite par l'addition de GDL dans nos essais a peut-être été trop faible $(-0,1$ unité) 
Tableau VI. Effet des différents traitements sur l'évolution au cours de l'affinage à $14^{\circ} \mathrm{C}$ de la proportion dans la caséine totale de la caséine $\alpha_{s 1}$ et de la fraction $\alpha_{s 1-1}$ (moyenne, écart type et analyse de la variance). a: essai 1 ; b: essai 2 .

Effects of the different treatments on the evolution of the proportion in whole casein of $\alpha_{s 1}$-casein and $\alpha_{s 1-1}$ fraction during cheese ripening at $14{ }^{\circ} \mathrm{C}$ (mean, SD and variance analysis). a: trial 1 ; $b$ : trial 2.

\begin{tabular}{llllllll}
\hline Variables & & & \multicolumn{3}{l}{ Stades d'affinage (essai 1) } \\
& J0 & J4 & & J8 & J12 & J26 & J40 \\
\hline
\end{tabular}

\section{a: essai 1}

\begin{tabular}{|c|c|c|c|c|c|c|c|}
\hline Caséine $\alpha_{\mathrm{s} 1}{ }^{a}$ & $\begin{array}{l}\bar{x} \\
s \\
s \\
\text { c }\end{array}$ & $\begin{array}{l}36,74 \\
( \pm 2,39) \\
N S\end{array}$ & $\begin{array}{l}38,52 \\
( \pm 2,50) \\
\text { NS }\end{array}$ & $\begin{array}{l}33,41 \\
( \pm 3,29) \\
\text { NS }\end{array}$ & $\begin{array}{l}35,00 \\
( \pm 2,74) \\
\text { NS }\end{array}$ & $\begin{array}{l}27,62 \\
( \pm 1,62) \\
N S\end{array}$ & $\begin{array}{l}21,61 \\
( \pm 1,07) \\
3 \underline{421}\end{array}$ \\
\hline Fraction $\alpha_{s 1^{-1}}$ a & $\begin{array}{l}\bar{X} \\
s \\
s \\
\text { C }\end{array}$ & $\begin{array}{l}1 \\
1 \\
1\end{array}$ & $\begin{array}{l}1 \\
1 \\
1\end{array}$ & $\begin{array}{l}4,44 \\
( \pm 0,39) \\
2143\end{array}$ & $\begin{array}{l}6,06 \\
( \pm 0,56) \\
2143\end{array}$ & $\begin{array}{l}11,86 \\
( \pm 0,82) \\
2143\end{array}$ & $\begin{array}{l}\begin{array}{l}15,95 \\
( \pm 0,89)\end{array} \\
1243\end{array}$ \\
\hline
\end{tabular}

b: essai 2

\begin{tabular}{|c|c|c|c|c|c|c|c|}
\hline Caséine $\alpha_{s 1}{ }^{a}$ & $\begin{array}{l}\bar{x} \\
s \\
s \\
c\end{array}$ & $\begin{array}{l}37,03 \\
2,38 \\
\text { NS }\end{array}$ & $\begin{array}{c}39,00 \\
1,76 \\
\text { NS }\end{array}$ & $\begin{array}{l}35,03 \\
2,21 \\
\text { NS }\end{array}$ & $\begin{array}{c}36,46 \\
1,71 \\
\text { NS }\end{array}$ & $\begin{array}{c}28,36 \\
2,54 \\
\text { NS }\end{array}$ & $\begin{array}{c}24,56 \\
0,77 \\
\text { NS }\end{array}$ \\
\hline Fraction $\alpha_{\mathrm{s} 1-1}{ }^{a}$ & $\begin{array}{l}\bar{X} \\
s \\
s \\
c\end{array}$ & $\begin{array}{l}1 \\
1 \\
1 \\
1\end{array}$ & $\begin{array}{l}1 \\
1 \\
1 \\
1\end{array}$ & $\begin{array}{l}3,25 \\
0,53 \\
* \\
3,12\end{array}$ & $\begin{array}{l}4,76 \\
0,42 \\
* * \\
3 \quad 12\end{array}$ & $\begin{array}{l}9,63 \\
0,23 \\
* \pm \\
312\end{array}$ & $\begin{array}{r}13,34 \\
0,45 \\
\ldots * \\
3 \quad 12\end{array}$ \\
\hline
\end{tabular}

a \% de la caséine totale; $\bar{X}$ : moyenne, $n=20$ (essai 1), $n=12$ (essai 2); : écart type; $S$ : seuil de signification, NS : non significatif; ${ }^{*}: P<0,05, \cdots: P<0,001 ; \mathrm{C}$ : classement après le test de Newman Keuls du plus grand au plus petit, 1 à $4: n^{\circ}$ des traitements de l'essai 1,1 à $3: n^{\circ}$ des traitements de l'essai 2 .

a $\%$ of whole casein; $\bar{X}$ : mean, $n=20$ (trial 1), $n=12$ (trial 2); $s$ : standard deviation; $S$ : Significance level; NS : Non Significant; ${ }^{\bullet}: \mathrm{P}<0.05, \cdots: \mathrm{P}<0.001 ; C$ : classification according to Newman-Keulstest from the largest to the smallest, 1 to 4 : treatment number in trial 1,1 to 3 : treatment number in trial 2.

pour provoquer une modification perceptible de l'activité de la chymosine dans la mesure où, par ailleurs les $\mathrm{pH}$ à l'emprésurage n'étaient pas tout à fait identiques d'un jour à l'autre des fabrications $(6,73 \pm 0,05)$.
Les résultats obtenus dans l'essai 2, entre les traitements chymosine mini et Endothia parasitica, sont similaires. Dans les conditions de fabrication des pâtes pressées cuites, la protéase d'Endothia pa- 
rasitica est totalement inactivée (Larson et Whitaker, 1970). D'autre part, cette enzyme ne dégrade pratiquement pas la caséine $\alpha_{\mathrm{s} 1}$, contrairement à la chymosine et à l'enzyme de Mucor miehei (Christensen et $a l$, 1989). Ces résultats laissent donc penser que dans les fromages issus du traitement chymosine mini, l'activité de la chymosine serait quasiment nulle.

Nos résultats confirment en grande partie et dans des conditions réelles de fabrication les résultats de Garnot et Mollé (1987). En particulier, ils montrent que si la quantité de chymosine retenue dans un caillé type fromages à pâte cuite pressée est très faible, l'activité résiduelle de cette enzyme dépend fortement de la température de chauffage en cuve. Comme eux, nous constatons qu'une température supérieure à $55^{\circ} \mathrm{C}$ provoque l'inactivation de cette enzyme, phénomène qui correspondrait à un changement de configuration de la molécule.

Dans ces conditions, si la seule activité chymosine présente dans les fromages à pâte cuite pressée résulte d'un chauffage modéré $\left(52^{\circ} \mathrm{C}\right)$ du mélange caillé-sérum en cuve, on peut se poser la question de l'agent responsable de la dégradation principale de la caséine $\alpha_{s 1}$. En effet, si l'on exprime la quantité de caséine $\alpha_{s 1}$ en $\%$ de I'ES des fromages, nous constatons que pour un affinage de 40 jours à $14{ }^{\circ} \mathrm{C}$, la caséine $\alpha_{\mathrm{s} 1}$ est dégradée à $63,8 \%$ (elle passe de $16,0 \mathrm{~g}$ à $5,8 \mathrm{~g} / 100 \mathrm{~g} \mathrm{ES}$ ) après un chauffage à $52{ }^{\circ} \mathrm{C}$ et seulement un peu moins, $60 \%$ (elle passe de 16,2 à $6,5 \mathrm{~g} /$ $100 \mathrm{~g} \mathrm{ES}$ ) après un chauffage du lait en cuve de $56^{\circ} \mathrm{C}$.

De nombreux agents protéolytiques peuvent être mis en cause. Kaminogawa et al (1980) ont montré qu'une enzyme naturelle du lait, la protéase acide est également capable de dégrader la caséine $\alpha_{\mathrm{s} 1}$ et de former des fragments $\alpha_{s 1-1}$. Cette en- zyme présente une bonne stabilité thermique et est donc capable de résister à l'étape de chauffage du caillé. Son pH optimal d'activité est cependant faible. La plasmine (protéase alcaline du lait) est, quant à elle, très active dans les caillés type pâte cuite pressée (Farkye et Fox, 1990), mais elle hydrolyse lentement la caséine $\alpha_{\mathrm{s} 1}$ pour produire des fractions de mobilité électrophorétique identique à celle des fractions caséines $\lambda$ (Grufferty et Fox, 1988). Si les streptocoques thermophiles sont peu protéolytiques et ne semblent pas hydrolyser la caséines $\alpha_{s 1}$ (Desmazeaud et Juge, 1976), les lactobacilles thermophiles hydrolysent partiellement les caséines $\alpha_{\mathrm{s}}$ et $\beta$ (El Soda et Desmazeaud, 1982; Zevaco et Gripon, 1988). Des enzymes de la flore de contamination des laits pourraient également participer à la dégradation de la caséines $\alpha_{\mathrm{s} 1}$.

En travaillant sur des caillés modèles aseptiques type Gouda, Visser et De Groot-Mostert (1977) ont montré que l'activité des levains mésophiles ne s'exerce sur la caséine $\alpha_{s 1}$ qu'après une période de latence de 1 mois. Après 2 mois d'affinage, l'hydrolyse de la caséine $\alpha_{\mathrm{s} 1}$ par ces levains est à peine de l'ordre de $10 \%$ et après 6 mois, elle atteint 40 à $50 \%$ de la caséine $\alpha_{s 1}$ initiale.

Dans nos fromages, l'hydrolyse de la caséine $\alpha_{\mathrm{s} 1}$ est précoce et rapide. Elle est déjà décelable au stade $\mathrm{J} 4$ par l'apparition de la fraction $\alpha_{s 1-1}$ et elle est très importante au stade $\mathrm{J} 40$ (pratiquement les $2 / 3$ de la caséine $\alpha_{s 1}$ hydrolysés).

Dans ces conditions, on peut admettre que dans les fromages à pâte cuite pressée, la dégradation de la caséine $\alpha_{\mathrm{s} 1}$ est probablement liée en début d'affinage à l'activité d'un système enzymatique présent dans les caillés frais. Les lactobacilles thermophiles utilisés en fabrication de pâtes cuites pressées sont plus protéolyti- 
ques que les bactéries mésophiles utilisées en fabrication de Gouda. On peut donc penser que la dégradation de la caséine $\alpha_{s 1}$ est plus rapide avec ceux-ci. D'autre part, l'activité des lactobacilles thermophiles diminue après un chauffage à $56^{\circ} \mathrm{C}$ (Castaneda et al, 1990). À partir de ces constatations, on peut imaginer que les lactobacilles sont les principaux responsables de la dégradation de la caséine $\alpha_{s 1}$ dans nos fromages.

\section{Dégradation des autres caséines}

La caséine $\beta$ représente $1 / 3$ de la caséine totale au stade J0. Son évolution au cours de l'affinage à $14^{\circ} \mathrm{C}$ pendant 40 jours est plus modérée que celle de la caséine $\alpha_{\mathrm{s} 1}$ : elle passe en moyenne pour les 2 séries d'essais de 14,7 à $10,2 \mathrm{~g} / 100 \mathrm{~g} \mathrm{ES}$, ce qui représente une hydrolyse de $30 \%$ environ.

Aucun des traitements technologiques étudié n'a d'effet significatif sur la vitesse de dégradation de la caséine $\beta$ (tableau VII), bien qu'on note une légère tendance à l'augmentation de l'hydrolyse de cette caséine après un chauffage en cuve de $56^{\circ} \mathrm{C}$ par rapport à un chauffage à $52^{\circ} \mathrm{C}$. Cette tendance est confirmée par une apparition un peu plus rapide des fractions $\gamma$ dans les fromages fabriqués à $56^{\circ} \mathrm{C}$ (essais 1 et 2). La différence est significative $(P<0,05)$ à partir de J26 (tableau VII et fig 3), mais faible puisqu'elle correspond en valeur absolue à environ 1,5 point d'écart de la proportion du total des fractions $\gamma$ dans l'ensemble des fractions caséines, soit un écart de $10 \%$ en valeur relative.

Parmi les fractions $\gamma$, la fraction $\gamma_{1}$, ne semble pas affectée. Comme elle correspond au fragment le plus long; on peut penser qu'elle ne constitue qu'une étape de l'hydrolyse de la caséine $\beta$. Collin et al
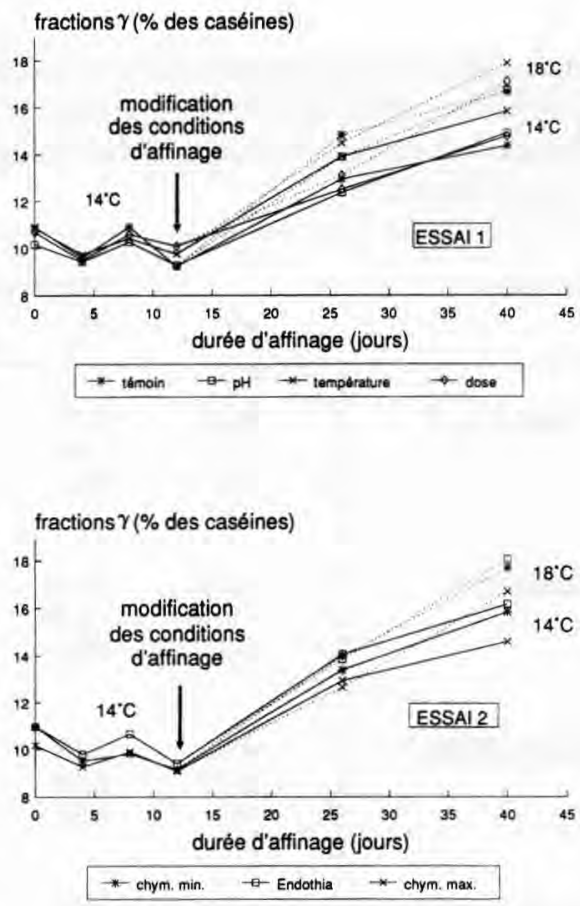

Fig 3. Évolution au cours de l'affinage des fractions $\gamma$ exprimée en $\%$ des caséines totales. Evolution during cheese ripening of the $\gamma_{s 1-1}$ fraction expressed as percentage of whole casein.

(1987) avaient déjà fait observer une différence de cinétique dans la production de la caséine $\gamma_{1}$ par rapport aux fractions $\gamma_{2}$ et $\gamma_{3}$ au cours de l'affinage du gruyère de Comté.

On sait que les fractions $\gamma$ sont les produits spécifiques de la dégradation de la caséine $\beta$ par la plasmine. Cette enzyme naturelle du lait est thermostable (Kaminogawa et al, 1972) et son activité est accrue après thermisation ou mieux, après pasteurisation du lait (Noomen, 1975; Richard- 
Tableau VII. Effet des différents traitements sur l'évolution au cours de l'affinage à $14^{\circ} \mathrm{C}$ de la proporécart type et analyse de la variance). a: essai 1 ; b: essai 2.

Effects of the different treatments on the evolution of proportions in whole casein of $\alpha_{s 2}, \beta$-caseins a: trial 1, b: trial 2 .

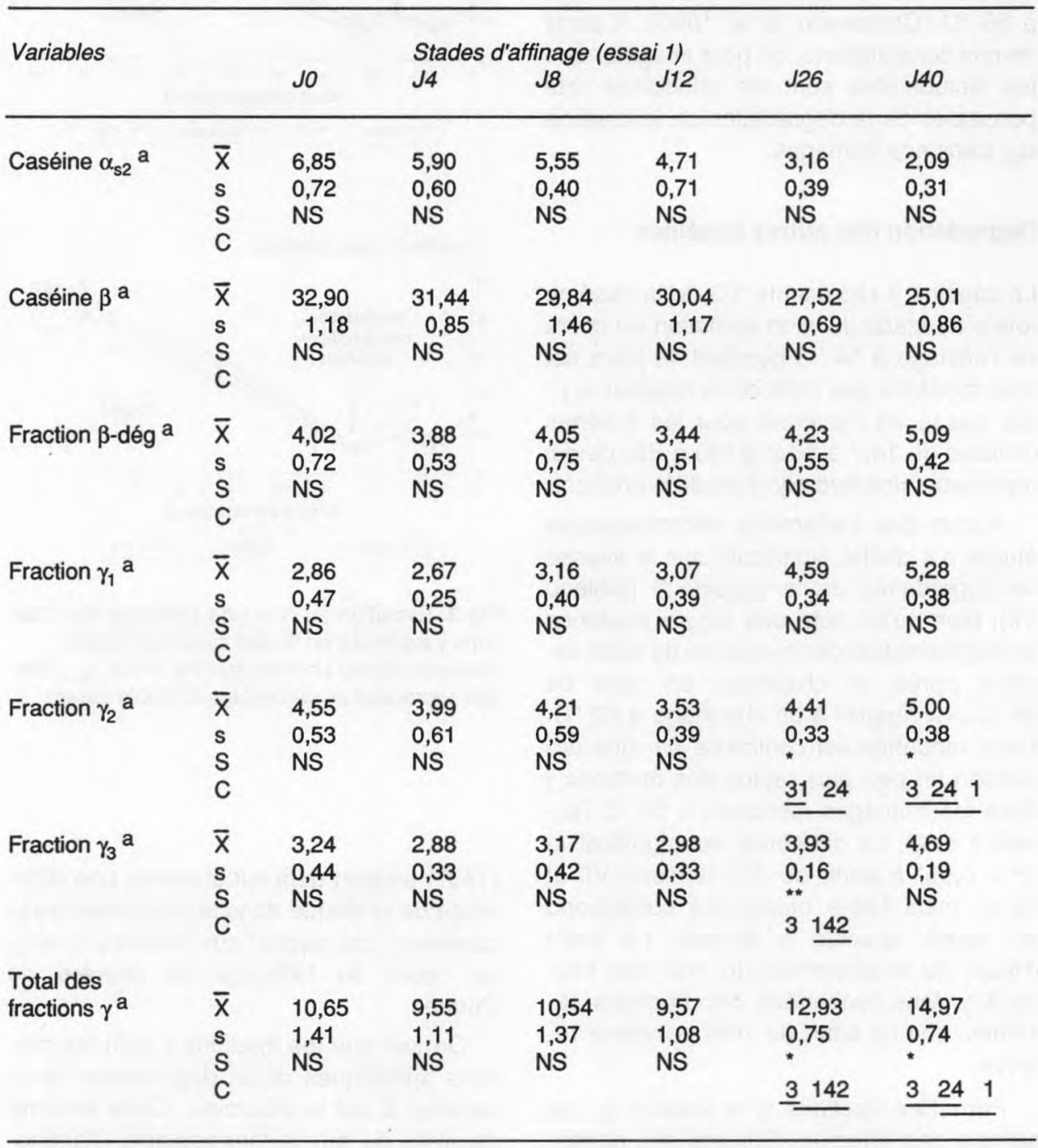

a \% de la caséine totale; $\mathrm{X}$ : moyenne, $n=20$ (essai 1), $n=12$ (essai 2); $\mathrm{s}$ : écart type; $\mathrm{S}$ : seuil de signification, plus petit, 1 à $4: n^{\circ}$ des traitements de l'essai 1,1 à $3: n^{\circ}$ des traitements de l'essai 2.

Non Significant; ${ }^{*}: \mathrm{P}<0.05,{ }^{* *}: \mathrm{P}<0.01 ; C$ : classification according to Newman-Keuls'test from the largest to 
tion dans la caséine totale des caséines $\alpha_{\mathrm{s} 2}, \beta$ et des fractions $\beta$ dégradées, $\gamma_{1}, \gamma_{2}$ et $\gamma_{3}$ (moyenne, and degraded $\beta, \gamma_{1}, \gamma_{2}$ and $\gamma_{3}$ fractions during ripening at $14^{\circ} \mathrm{C}$ (mean, SD and variance analysis).

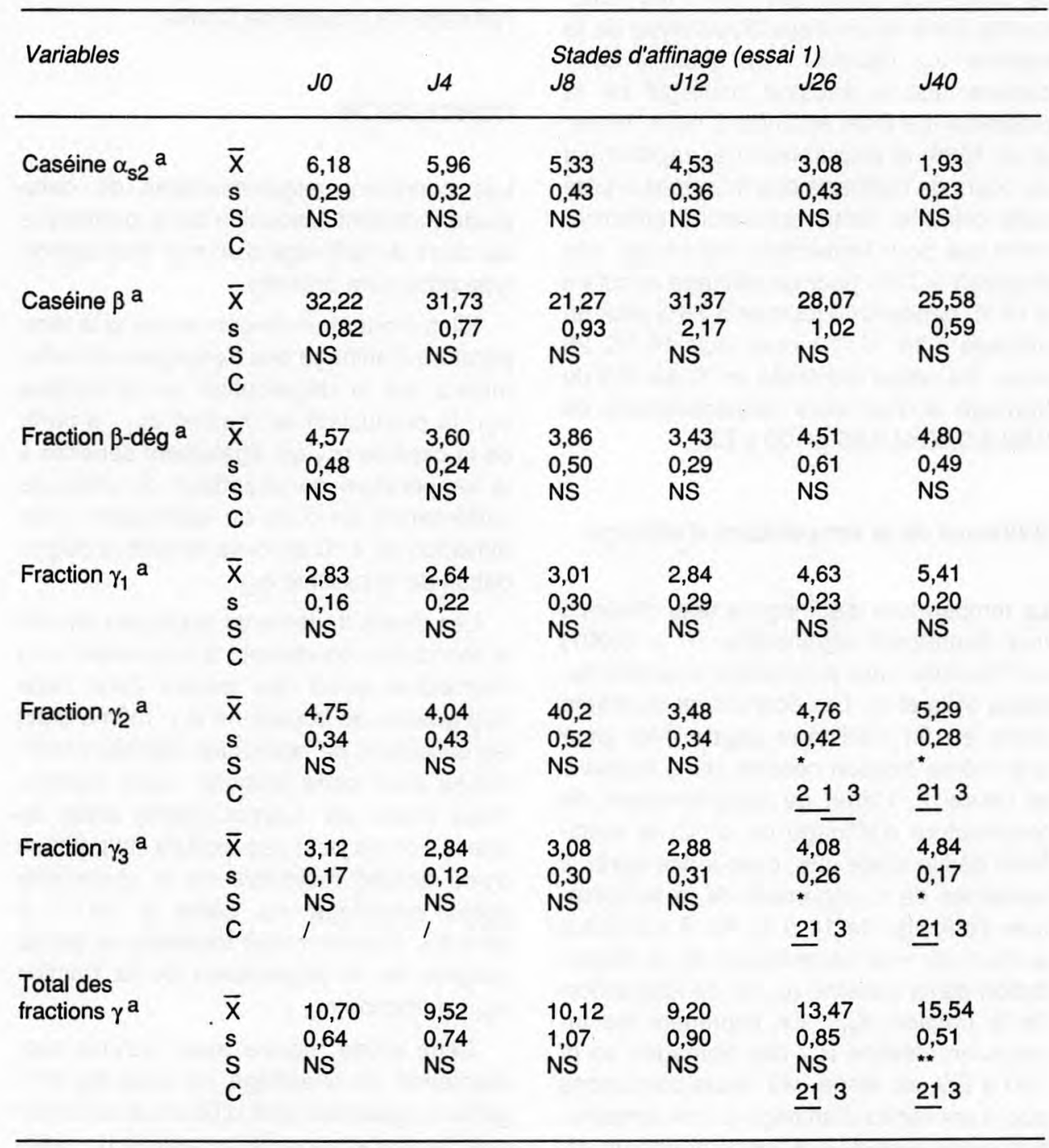

NS : non significatif; ${ }^{*}: P<0,05,{ }^{* *}: P<0,01 ; C$ : classement après le test de Newman Keuls du plus grand au a $\%$ of whole casein; $X$ : mean, $n=20$ (trial 1), $n=12$ (trial 2); $s$ : standard deviation; S : Significance level; NS : the smallest, 1 to 4 : treatment number in trial 1,1 to $3:$ treatment number in trial 2 . 
son, 1983). II semble donc que l'activation du système enzymatique "plasmine" soit déjà effective pour un écart de chauffage du lait de $4^{\circ} \mathrm{C}$.

Nous n'avons cependant pas observé de différence, quels que soient les traitements, dans la cinétique d'hydrolyse de la caséine $\alpha_{\mathrm{s} 2}$ (tableau VII), quoique cette caséine soit le substrat privilégié de la plasmine (Le Bars et Gripon, 1989; Visser et $a l, 1989$ ) et disparaisse très rapidement au cours de l'affinage des fromages à pâte cuite pressée. Nous constatons effectivement que pour l'ensemble des essais, elle disparaît à $72 \%$ pour un affinage constant à $14^{\circ} \mathrm{C}$ pendant 40 jours et à $78 \%$ pour un affinage à $14^{\circ} \mathrm{C}, 12$ jours, puis $18^{\circ} \mathrm{C}, 28$ jours. Sa valeur exprimée en $\%$ de l'ES du fromage évolue alors respectivement de 2,90 à 0,80 et $0,65 \mathrm{~g} / 100 \mathrm{~g} \mathrm{ES}$.

\section{Influence de la température d'affinage}

La température d'affinage a une influence très hautement significative $(P<0,001)$ sur l'évolution des principales caséines (tableau VIIla et b). Les écarts sont du même ordre en fin d'affinage (stade $\mathrm{J40}$ ) pour une même fraction caséine dans l'essai 1 et l'essai 2. L'effet de l'augmentation de température d'affinage de $4^{\circ} \mathrm{C}$ se manifeste dès le stade J26, c'est-à-dire après 2 semaines de changement de la température d'affinage de 14 à $18^{\circ} \mathrm{C}$. II se traduit surtout par une accélération de la dégradation de la caséine $\alpha_{\mathrm{s} 1}$ et de l'apparition de la fraction $\alpha_{s 1-1}$. En exprimant les teneurs en caséine $\alpha_{\mathrm{s} 1}$ des fromages en $\mathrm{g} /$ $100 \mathrm{~g} \mathrm{ES}$, au stade $\mathrm{J} 40$, nous constatons que 4 semaines d'affinage à une température supérieure de $4^{\circ} \mathrm{C}$ ont entraîné un ac- croissement de l'hydrolyse de cette caséine de $30 \%$ dans l'essai 1 comme dans l'essai 2 (tableau IX). Collin et al (1987) avaient déjà montré que la température d'affinage jouait un rôle primordial dans la dégradation de la caséine $\alpha_{\mathrm{s} 1}$ en cours de l'affinage du gruyère de Comté.

\section{CONCLUSION}

Les conditions expérimentales de cette étude montrent l'évolution de la protéolyse au cours de l'affinage d'un mini fromage de type pâte cuite pressée.

Elles mettent en évidence que si la température d'affinage des fromages a un effet majeur sur la dégradation de la caséine $\alpha_{s 1}$, la production de fraction $\alpha_{s 1-1}$ à partir de la caséine $\alpha_{s 1}$ est également sensible à la température de chauffage du mélange caillé-sérum en cuve de fabrication : une élévation de $4^{\circ} \mathrm{C}$ en cuve ralentit la dégradation de la caséine $\alpha_{s 1}$.

Les divers traitements appliqués lors de la fabrication conduisent à n'accorder à la chymosine qu'un rôle mineur dans cette dégradation de la caséine $\alpha_{\mathrm{s} 1}$, même dans les conditions de fabrication estimées favorables pour cette enzyme. Ceci confime l'idée émise par Garnot (1985) selon laquelle "on ne peut pas exclure l'hypothèse d'une activité résiduelle de la chymosine après chauffage du caillé à $53^{\circ} \mathrm{C}$ à $\mathrm{pH} 6,5$ ". II conviendrait toutefois de définir l'origine de la dégradation de la fraction $\alpha_{s 1}$ en fraction $\alpha_{s 1-1}$.

Cette étude montre aussi qu'une augmentation du chauffage en cuve de $4^{\circ} \mathrm{C}$ génère également une différence de cinétique de dégradation de la caséine $\beta$ : celle- 
Tableau VIII. Influence de la température d'affinage sur l'évolution des proportions dans la caséine totale des principales fractions caséines $\left(\alpha_{s 1}, \alpha_{s 1-1}, \alpha_{s 2}, \beta\right.$ et $\left.\gamma\right)$ (moyenne, écart type et analyse de la variance). a: essai 1 ; b: essai 2 .

Influence of ripening temperature on the evolution of proportion in whole casein of main casein fractions $\left(\alpha_{s 1}, \alpha_{s 1-k} \alpha_{s 2}, \beta\right.$ and $\left.\gamma\right)$ (mean, SD and variance analysis). a: trial 1; b: trial 2.

Stades d'affinage (essai 1)

\begin{tabular}{lllll}
\cline { 2 - 4 } & \multicolumn{2}{c}{26 jours } & \multicolumn{2}{c}{40 jours } \\
Variables & $\begin{array}{c}\text { Températures d'affinage } \\
14^{\circ} \mathrm{C} \quad 18^{\circ} \mathrm{C}\end{array}$ & $S$ & $\begin{array}{c}\text { Températures d'affinage } \\
14^{\circ} \mathrm{C}\end{array}$ & $S$ \\
\hline
\end{tabular}

\begin{tabular}{|c|c|c|c|c|c|c|}
\hline Caséine $\alpha_{\mathrm{s} 1}{ }^{a}$ & $\begin{array}{c}27,62 \\
( \pm 1,48)\end{array}$ & $\begin{array}{c}22,70 \\
( \pm 0,86)\end{array}$ & $* * *$ & $\begin{array}{c}21,61 \\
( \pm 0,98)\end{array}$ & $\begin{array}{c}15,39 \\
( \pm 1,23)\end{array}$ & $* * *$ \\
\hline Fraction $\alpha_{s 1-1}{ }^{a}$ & $\begin{array}{c}11,86 \\
( \pm 0,75)\end{array}$ & $\begin{array}{c}15,59 \\
( \pm 0,89)\end{array}$ & $* * *$ & $\begin{array}{c}15,95 \\
( \pm 0,82)\end{array}$ & $\begin{array}{c}20,22 \\
( \pm 0,97)\end{array}$ & 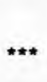 \\
\hline Caséine $\alpha_{\mathrm{s} 2}{ }^{a}$ & $\begin{array}{c}3,16 \\
( \pm 0,36)\end{array}$ & $\begin{array}{c}2,71 \\
( \pm 0,34)\end{array}$ & $* * *$ & $\begin{array}{c}2,09 \\
( \pm 0,29)\end{array}$ & $\begin{array}{r}1,66 \\
( \pm 0,16)\end{array}$ & $* * *$ \\
\hline Caséine $\beta^{a}$ & $\begin{array}{c}27,52 \\
( \pm 0,64)\end{array}$ & $\begin{array}{c}26,79 \\
( \pm 1,18)\end{array}$ & NS & $\begin{array}{c}25,01 \\
( \pm 0,79)\end{array}$ & $\begin{array}{c}23,62 \\
( \pm 1,06)\end{array}$ & $\star * *$ \\
\hline $\begin{array}{l}\text { Total des } \\
\text { fractions } \gamma \text { a }\end{array}$ & $\begin{array}{c}12,93 \\
( \pm 0,69)\end{array}$ & $\begin{array}{c}14,08 \\
( \pm 0,93)\end{array}$ & $* * *$ & $\begin{array}{c}14,97 \\
( \pm 0,68)\end{array}$ & $\begin{array}{c}17,10 \\
( \pm 1,14)\end{array}$ & $* * *$ \\
\hline \multicolumn{7}{|l|}{ b: essai 2} \\
\hline Caséine $\alpha_{\mathrm{s} 1}$ a & $\begin{array}{c}27,10 \\
( \pm 1,81)\end{array}$ & $\begin{array}{c}24,38 \\
( \pm 0,98)\end{array}$ & $* * *$ & $\begin{array}{c}24,20 \\
( \pm 0,89)\end{array}$ & $\begin{array}{c}17,35 \\
( \pm 0,56)\end{array}$ & $* * *$ \\
\hline Fraction $\alpha_{s 1-1}{ }^{a}$ & $\begin{array}{c}10,27 \\
( \pm 0,55)\end{array}$ & $\begin{array}{c}15,45 \\
( \pm 1,05)\end{array}$ & $* *$ & $\begin{array}{c}13,70 \\
( \pm 0,47)\end{array}$ & $\begin{array}{c}19,28 \\
( \pm 0,90)\end{array}$ & $* * *$ \\
\hline Caséine $\alpha_{\mathrm{s} 2}{ }^{a}$ & $\begin{array}{c}3,08 \\
( \pm 0,38)\end{array}$ & $\begin{array}{c}2,73 \\
( \pm 0,44)\end{array}$ & NS & $\begin{array}{c}1,93 \\
( \pm 0,21)\end{array}$ & $\begin{array}{c}1,62 \\
( \pm 0,19)\end{array}$ & $\star \star$ \\
\hline Caséine $\beta$ a & $\begin{array}{c}28,07 \\
( \pm 0,93)\end{array}$ & $\begin{array}{c}26,42 \\
( \pm 0,75)\end{array}$ & $* * *$ & $\begin{array}{c}25,58 \\
( \pm 0,53)\end{array}$ & $\begin{array}{c}23,60 \\
( \pm 0,92)\end{array}$ & *** \\
\hline $\begin{array}{l}\text { Total des } \\
\text { fractions } \gamma^{\text {a }}\end{array}$ & $\begin{array}{c}13,47 \\
( \pm 0,77)\end{array}$ & $\begin{array}{c}13,50 \\
( \pm 0,81)\end{array}$ & NS & $\begin{array}{c}15,54 \\
( \pm 0,46)\end{array}$ & $\begin{array}{c}17,48 \\
( \pm 0,63)\end{array}$ & $* *$ \\
\hline
\end{tabular}

a \% de la caséine totale; $S$ : seuil de signification, NS : non significatif; ${ }^{* *}: P<0,01 ;{ }^{* * *}: P<0,001$.

${ }^{a} \%$ of whole casein; $S$ : Significance level; NS : Non Significant; ${ }^{*}: \mathrm{P}<0.01 ;{ }^{\cdots *}: \mathrm{P}<0.001$. 
Tableau IX. Influence de la température d'affinage sur la teneur en fractions caséines (en g/100 g d'extrait sec) au stade $\mathrm{J} 40$ (essais 1 et 2).

Influence of the ripening temperature on the amount of casein fractions (expressed in $\mathrm{g} / 100 \mathrm{~g}$ of dry matter) after 40 days ripening (trials 1 and 2).

\begin{tabular}{|c|c|c|c|c|c|c|}
\hline \multirow[b]{2}{*}{ Variables } & \multicolumn{3}{|c|}{ Essai 1} & \multicolumn{3}{|c|}{ Essai 2} \\
\hline & \multicolumn{2}{|c|}{$\begin{array}{l}\text { Températures d'affinage } \\
14^{\circ} \mathrm{C} \quad 18^{\circ} \mathrm{C}\end{array}$} & $S$ & \multicolumn{2}{|c|}{ Température d'affinage } & $s$ \\
\hline Caséine $\alpha_{\mathrm{s} 1}{ }^{a}$ & $\begin{array}{r}8,70 \\
( \pm 0,41)\end{array}$ & $\begin{array}{r}6,00 \\
( \pm 0,55)\end{array}$ & $* * *$ & $\begin{array}{c}9,76 \\
( \pm 0,42)\end{array}$ & $\begin{array}{c}6,81 \\
( \pm 0,35)\end{array}$ & $* * *$ \\
\hline Fraction $\alpha_{s 1-1}{ }^{a}$ & $\begin{array}{r}6,42 \\
( \pm 0,32)\end{array}$ & $\begin{array}{c}7,88 \\
( \pm 0,40)\end{array}$ & $* * *$ & $\begin{array}{c}5,53 \\
( \pm 0,22)\end{array}$ & $\begin{array}{c}7,56 \\
( \pm 0,46)\end{array}$ & *** \\
\hline Caséine $\alpha_{s 2}{ }^{a}$ & $\begin{array}{c}0,84 \\
( \pm 0,12)\end{array}$ & $\begin{array}{c}0,65 \\
( \pm 0,06)\end{array}$ & $\star \star \star \star$ & $\begin{array}{c}0,78 \\
( \pm 0,09)\end{array}$ & $\begin{array}{c}0,64 \\
( \pm 0,08)\end{array}$ & ** \\
\hline Caséine $\beta$ a & $\begin{array}{c}10,07 \\
( \pm 0,35)\end{array}$ & $\begin{array}{c}9,21 \\
( \pm 0,50)\end{array}$ & $* * \star$ & $\begin{array}{c}10,32 \\
( \pm 0,30)\end{array}$ & $\begin{array}{r}9,25 \\
( \pm 0,53)\end{array}$ & $* * *$ \\
\hline $\begin{array}{l}\text { Total des } \\
\text { fractions } \gamma^{\text {a }}\end{array}$ & $\begin{array}{c}6,03 \\
( \pm 0,30)\end{array}$ & $\begin{array}{c}6,66 \\
( \pm 0,38)\end{array}$ & $* * *$ & $\begin{array}{c}3,71 \\
( \pm 0,33)\end{array}$ & $\begin{array}{c}6,09 \\
( \pm 0,26)\end{array}$ & $* * *$ \\
\hline
\end{tabular}

a $\%$ de la caséine totale; $S$ : seuil de signification, NS : non significatif; ** : $P<0,01 ; \cdots * P<0,001$.

$a$ \% of whole casein; $S$ : Significance level; NS : Non Significant; ${ }^{\cdots *}: \mathrm{P}<0.01 ;{ }^{* *}: \mathrm{P}<0.001$.

ci est accentuée avec formation plus rapide des fractions $\gamma$, action liée à l'activation de la plasmine ou du plasminogène.

Une analyse factorielle discriminante réalisée à partir des données expérimentales de l'essai 1 résume parfaitement ces résultats (fig 4). Deux variables, la proportion de fraction $\alpha_{s 1-1}$ et celle de fraction $\gamma_{3}$ dans la caséine totale, discriminent bien suivant l'axe 2 , les fromages affinés à $18^{\circ} \mathrm{C}$ des fromages affinés à $14^{\circ} \mathrm{C}$, et suivant l'axe 1, les fromages fabriqués à $56^{\circ} \mathrm{C}$ (traitement 3) des fromages fabriqués à $52^{\circ} \mathrm{C}$ (traitements 1,2 et 4 ). L'effet négatif du traitement technologique 3 sur la production du fragment $\alpha_{s 1-\mid}$ persiste du stade J26 au stade J40, bien que l'effet positif de l'affinage à $18^{\circ} \mathrm{C}$ sur l'hydrolyse de la caséine $\alpha_{s 1}$ augmente d'un stade d'affinage à l'autre.

\section{REMERCIEMENTS}

Ce programme a reçu une aide financière de la région Franche-Comté (contrat $3202 \mathrm{~A}$ ). Nous remercions également G Duboz de I'INRA Poligny pour sa contribution technique à la réalisation des fabrications fromagères et $C$ André de I'ITG, zone sud, pour la dactylographie du présent article. 
a

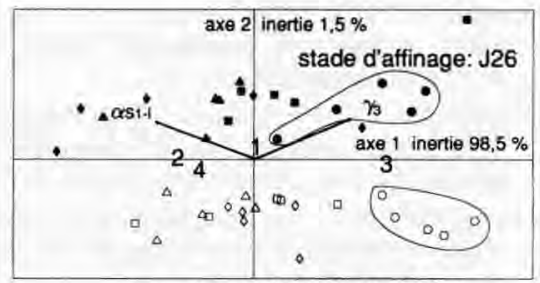

pourcentage de bien classés: $50,0 \%$

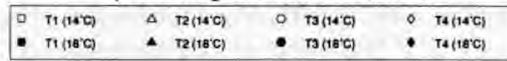

b

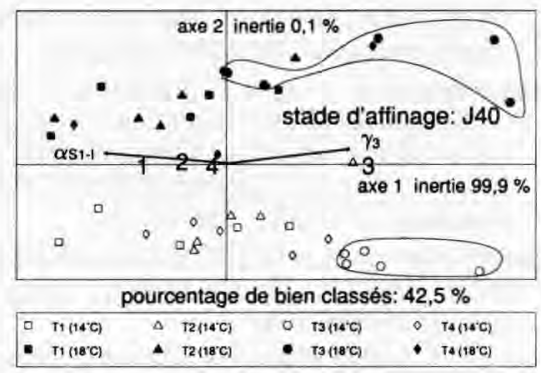

Fig 4. Analyse factorielle discriminante aux stades J26 (a) et J40 (b) des fromages fabriqués suivant 4 technologies et affinés à 2 cycles différents de température à partir de 2 variables : les fractions $\alpha_{s 1-1}$ et $\gamma_{3}$ exprimées en $\%$ des caséines totales.

Discriminant analysis after 26 and 40 days ripening of cheeses made according to 4 different processes and ripened according to 2 different temperature cycles with 2 variables : $\alpha_{s 1-1}$ and $\gamma_{3}$ fractions expressed as percentage of whole casein.

\section{RÉFÉRENCES}

Bellon JL, Quiblier JP, Durier C, Noël Y (1988) Un nouveau capteur industriel de mesure du temps de coagulation du lait. Tech Lait Market 1033, 29-32

Benslimane S, Dognin-Bergeret MJ, Berdagué JL, Gaudemer Y (1990) Variation with season and lactation of plasmin and plasminogen concentrations in Montbeliard cows' milk. J Dairy Res 57, 423-435

Buchet C (1987) Essai de quantification des caséines des fromages à pâte cuite pressée sé- parées par électrophorèse sur gel PAGE. Etude ITG, non publiée, $20 \mathrm{p}$

Castaneda R, Vassal L, Gripon JC, Rousseau M (1990) Accelerated ripening of a Saint-Paulin cheese variant by addition of heat-shocked Lactobacillus suspensions. Neth Milk Dairy J 44, 49-62

Christensen TMIE, Christiansen KR, Madsen JS (1989) Proteolysis in cheese investigated by high performance liquid chromatography. J Dairy Res 56, 823-828

Collin JC, Berdagué JL, Dognin-Bergeret $M$, Grappin R (1987) Affinage et qualité du gruyère de Comté. IV. Étude de la protéolyse. Lait 67, 299-318

Collin JC, Compagnone P, Ryba I, Baer A (1988) Determination of plasmin (alkaline milk proteinase) and chymosin in milk products by the ELISA assay. Lait $68,235-239$

Dahlquist FW, Long JW, Bigbee WL (1976) Role of calcium in the thermal stability of thermolysin. Biochemistry 15, 1103-1111

Desmazeaud MJ, Juge M (1976) Caractérisation de l'activité protéolytique et fractionnement des dipeptidases et des aminopeptidases de Streptococcus thermophilus. Lait 56, 241-260

Desmazeaud MJ, Gripon JC, Lebars D, Bergère JL (1976) Étude du rôle des microorganismes et des enzymes au cours de la maturation des fromages. III. Influence des microorganismes. Lait 56, 379-396

El Soda M, Desmazeaud MJ (1982) Les peptides hydrolases des lactobacilles du groupe thermobacterium. I. Mise en évidence de ces activités chez $L$ helveticus, $L$ acidophilus, $L$ lactis, $L$ bulgaricus. Can J Microbiol 28, 1181-1188

Farkye NY, Fox PF (1990) Observations on plasmin activity in cheese. J Dairy Res 57 , 413-418

FIL (1982) Fromages et fromages fondus. Détermination de l'extrait sec total, méthode de référence, norme $4 \mathrm{~A}$

Garnot P (1985) Heat-stability of milk-clotting enzymes. Technological consequences. Bull Fed Int Lait 194, 2-7

Garnot P, Mollé D (1987) Heat stability of milk clotting enzymes in conditions encountered in Swiss cheese making. J Food Sci 52, 7577

Grappin R, Berdagué JL (1989) Affinage et qualité du gruyère de Comté. VIII. Synthèse et conclusions. Lait 69, 183-196 
Green ML, Foster PMD (1974) Comparison of the rates of proteolysis during ripening of Cheddar cheeses made with calf rennet and swine pepsin coagulants. J Dairy Res 41 , 269-282

Gripon JC, Desmazeaud MJ, Lebars D, Bergère JL (1975) Étude du rôle des microorganismes et des enzymes au cours de la maturation des fromages. II. Influence de la présure commerciale. Lait $55,502-513$

Grufferty MB, Fox PF (1988) Milk alkaline protease. J Dairy Res 55, 609-630

Heiss E (1961) Essai de dosage de la matière grasse dans le fromage par des méthodes rapides. Disch Molk Ztg 82, 67-70

Holmes DG, Duersch JW, Ernstrom CA (1977) Distribution of milk clotting enzymes between curd on whey and their survival during Cheddar cheese making. J Dairy Sci 60, 862-869

Kaminogawa S, Mizobuchi $H$, Yamauchi K (1972) Comparison of bovine milk protease with plasmin. Agric Biol Chem 36, 21632167

Kaminogawa S, Yamauchi K, Miyazama S, Koga Y (1980) Degradation of casein components by acid protease of bovine milk. $J$ Dairy Sci 63, 701-704

Kleter G (1976) The ripening of Gouda cheese made under strict aseptic conditions. 1. Cheese with no other bacterial enzymes than those from a starter Streptococcus. Neth Milk Dairy J 30, 254-270

Kuchroo CN, Fox PF (1982) Soluble nitrogen in Cheddar cheese. Milchwissenschaft 37, 331335

Larson MK, Whitaker JR (1970) Endothia parasitica protease. Parameter affecting stability of the rennin like enzyme. J Dairy Sci 53, 262-269

Le Bars D, Gripon JC (1989) Specificity of plasmin towards bovine $\alpha_{\mathrm{s} 2}$-casein. J Dairy Res $56,817-821$

Ledford RA, O'Sullivan AC, Nath KR (1966) Residual casein fractions in ripened cheese determined by polyacrylamide-gel electrophoresis. J Dairy Sci 49, 1098-1101

Matheson AR (1981) The immunochemical determination of chymosin activity in cheese. NZJ Dairy Sci Technol 15, 33-41

Mulvihill DM, Fox PF (1979) Proteolytic specificity of chymosin on bovine $\alpha_{s 1}$-casein. $J$ Dairy Res 46, 641-651
Noomen A (1975) Proteolytic activity of milk protease in raw and pasteurized cow's milk. Neth Milk Dairy J 29, 153-161

O'Keefe AM, Fox PF, Daly G (1978) Proteolysis in Cheddar cheese: role of coagulant and starter bacteria. J Dairy Res 45, 405-477

Pearce KN (1977) The complexometric determination of calcium in dairy products. NZJ Dairy Sci Technol 12, 113-115

Richardson BC (1983) The proteinases of bovine milk and the effect of pasteurisation on their activity. NZJ Dairy Sci Technol 18, 233-245

Sanogo T, Paquet D, Linden G (1987) Protéolyse de la caséine bovine en milieu salin : étude de quatre protéases. Sci Alim 7, 385-398

Serpelloni M, Dusautois C, Boudier JF, Lablée J, Mietton B (1989) Intérêt de la gluconodelta-lactone dans la standardisation des laits de fromagerie : optimisation du $\mathrm{pH}$ d'emprésurage. Rev ENIL 133, 26-33

Stadhouders J, Hup G (1975) Factors affecting bitter flavour in Gouda cheese. Neth Milk Dairy J 29, 335-353

Trossat P (1988) Étude du rôle de la plasmine sur la protéolyse et la texture des fromages à pâte pressée cuite. Rapport DEA, univ $\mathrm{Be}$ sançon, $25 \mathrm{p}$

Uriel J (1966) Méthode d'électrophorèse dans des gels d'acrylamide-agarose. Bull Soc Chim Biol 48, 969-982

Vassal L, Gripon JC (1984) L'amertume des fromages à pâte molle de type camembert : rôle de la présure et de Penicillium caseicolum, moyens de la contrôler. Lait 64, 397-417

Visser FMW (1977) Contribution of enzymes from rennet, starter bacteria and milk to proteolysis and flavour development in Gouda cheese. 3. Protein breakdown: analysis of the soluble nitrogen and amino acid fractions. Neth Milk Dairy J 31, 210-239

Visser FMW, De Groot-Mostert AEA (1977) Contribution of enzymes from rennet, starter bacteria and milk to proteolysis and flavour development in Gouda cheese. 4. Protein breakdown: a gel electrophoretical study. Neth Milk Dairy J 31, 247-264

Visser FMW, Slangen KJ, Alting AC, Vreeman H (1989) Specificity of bovine plasmin in its action on bovine $\alpha_{\mathrm{s2}}$-casein. Milchwissenschaft 44, 335-339

Zevaco C, Gripon JC (1988) Properties and specificity of a cell-wall proteinase from Lactobacillus helveticus. Lait $68,393-408$ 